\title{
Research on Application and Practice of Information Management in Automobile Die Manufacturing Industry
}

\author{
Lin Chengquan \\ Electrical and Mechanical Engineering College, Jingzhou Institute of Technology, Hubei ,434100, \\ China. \\ linchengquan@msn.com
}

Keywords: Information management, automobile mold, mold manufacturing, cost control

\begin{abstract}
In this paper, the information of Internet and enterprise and customer information exchange communication bridge tool, study of the key components of the automobile manufacture of manufacturing applications, and stamping die design and manufacturing, from the six case analysis, mold manufacturing, cost control, information management and sharing many aspects are studied and put forward the corresponding steps and measures, these measures will accelerate the development of the automotive industry mold design and manufacturing technology.
\end{abstract}

\section{Introduction}

In general, all the mold enterprises are small and medium-sized enterprises, mostly from a workshop style enterprise growth, even there are still many mold enterprises are workshop style of management, but in the automotive tooling delivery time, cost, quality control aspects of the problem a continuous layer. Facing the fierce competition in the car market, backward management means and level, automotive die enterprise management and technical personnel only exhausted, major car manufacturers voted heavily in the introduction of CAD/CAM systems and high-end CNC machining equipment is difficult to play a proper efficiency and level, enterprises lack of vitality and competitiveness. These problems have caused many ambition international advanced level par automotive die enterprise managers attach great importance to, how to improve the management level of enterprises, enhance the competitiveness of enterprises has become China's automobile mould manufacturing industry to participate in international competition in the market is an urgent need to solve the problem.

Therefore, automobile die manufacturing enterprises to improve the management level, with rapid response and timely adjustment of the ability, not a set of advanced management system to achieve the management of information management is very difficult to do. It is an effective way to improve the management level of the enterprise to realize the integrated management of the automobile mould manufacturing enterprise through the construction of the information management.

The through the mold enterprise practical case, discuss and analysis the information management to improve the importance and necessity of the management level of enterprises of automobile mould, and combined with the automobile manufacturing mould development Co., Ltd. has developed a professional mold enterprise management system (so mold making management), given the information management solutions.

\section{Information Technology is the Bridge between Internet + Enterprise and Customer Information Exchange}

Automotive tooling is a typical single piece of the production of the industry, each order has a detailed business and technical aspects of communication with customers, otherwise it will have serious consequences. Below is the automobile mold enterprise and the customer information communication is not sufficient two examples: 
Case 1. A large mold factory to undertake a new customer car mold orders, the automobile customer habits orders issued, and mold factory designers were detailed technical communication, put forward a detailed design requirements for auto parts mold, mold factory in accordance with the requirements of design, do not need to confirm the design drawings. And after the completion of the design personnel in the design of mold factory, but still as usual after the habit of other previous customer orders, waiting for customers to confirm the design after ordering mold and material, has been 10 days, to know the customer does not need to confirm the drawings. As a result, the set of mold extension of 10 days, the customer is not satisfied, no longer under the order, for this loss of a very potential customers.

Case 2. A mold factory to undertake the mold orders from a new customer, the customer of the injection molding factory has a strict safety standards -- how many tons of mold must use the rings. Due to the lack of detailed technical communication, the problem has been neglected. Mold design personnel in accordance with the habit of the plant selection of rings, the results than the standard of customer small a specification, causes the mold delivery of customers, only to find that does not meet the requirements, only to die shipped back, re processing rings hole, the whole process cost more than greatly exceeded, at the same time also affected the production of customer.

Thus, in communication with the customer and the enterprise interior even a small mistake, will cause a great loss to the enterprises. Therefore, to solve the problem of good communication, has the following important significance:

As far as possible to the mold business and technical aspects of the requirements of a comprehensive, to avoid repeated, so as to save costs and time.

Detailed understanding of the customer's mold technical requirements, to avoid in the test mode to modify and rework.

To record and summarize the contents of each communication, to establish customer service and technical knowledge base for each customer, to share in the company, so as to improve the customer service level and reduce the error.

The information management system will be able to help the mold enterprise to better communicate with customers. For example, in the Mold Making Management inte system, providing a detailed template technology communication template, template integration of domestic and foreign experience of many outstanding mold enterprises, and fully integrated with the international mold industry. Through the template, to facilitate the detailed technical communication with customers, reduce the mold modification work. And through the system records and customer communication information, you can sum up the customer business and technical aspects of the habit, to share the company's internal personnel, to avoid repeating the mistakes.

\section{Information Management System can Help Enterprises to Monitor the Progress of the Mold}

Customers are very concerned about the mold test mode and delivery date, often based on mold mold trial schedule trial production and production plan, especially overseas customers tend to delivery of the mold of the importance in the first place. Therefore, the control of the production and production period of the mold is an important indicator of the enterprise to win in the market competition. The following case may be a lot of mold factory has been a problem.

Case 3. A large automobile mold factory to undertake the South African customer mold orders, due to the lack of effective monitoring and control of the mold production schedule and management tools, can not schedule. Production department has made the situation feedback to the overseas market, but market personnel due to not understanding the production of the actual situation that fails to test the client module will not be happy, then hold fluky mentality that the production department to work overtime rush back in time remains committed to customer established mold trial date. When the customer from ten thousand miles outside to look at the model, found that the mold in a week can not test mode. Customer is very disappointed, no longer under the order. 
The root cause of the failure of the mold process monitoring:

The lack of effective monitoring means for the production schedule of automobile dies can not find the problems in the production process of automobile dies in time.

Automobile mould production process cannot get effective feedback and record, often by intuition to judge the car mold process, the habit of using "almost, far worse, soon finished" fuzzy concept to illustrate the progress of the data is not accurate and timely, often produce luck.

The lack of information sharing environment and platform. Due to the different nature of each person's work, the knowledge of the actual manufacturing process of each mold has great difference and through stepped layers of information feedback tends to cause information distortion, coupled with human factors problems.

People often pay more attention to the important and difficult problems, ignore small problems, especially when the enterprise at the same time, there are dozens or hundreds of sets in different stages in the mold, the management personnel is difficult to adhere to every day have taken the trouble to check each set of mold of each task process is included in the plans.

The information management system will provide a shared, consistent and faithful process monitoring platform for the enterprise. For example, in so mold making management system, through the project plan and process control can die on the whole life cycle (to determine the order, design, procurement, production, first try mould modification delivery) management. Management personnel at the first production line directly in the system feedback the actual progress of the mold, the system faithfully monitor every task of the project process, when a control point extension, the system will automatically send alarm message to the relevant personnel, for early detection, early settlement. And, for some of the key tasks, but also allows the system to early warning, so that the relevant personnel to prepare and arrange early.

\section{Effective Automobile Die Cost Control and Information Technology}

Cost control is one of the difficult points in the management of automobile die and mould enterprise. The cost control ability of the mould manufacturing enterprise is more and more outstanding. At present, the automobile die industry is facing heavy pressure mold prices getting lower and lower, automobile mould increased revised several times, profit of automobile die on the consumption of clean, even to sustain losses in business. If the enterprise can not fundamentally solve the problem, will face the risk of elimination out of the.

In the specialized mold enterprise management system Mold Making Management inte, will help the enterprise to control the cost through the following way:

Within the company issued orders, to quote the cost estimation based, for the mold making cost planning; cost early warning system, mold production cost elements of monitoring, so as to effectively control the costs, to ensure a successful conclusion of the target profit.

When the automobile die BOM is issued, the difference between the total material cost and the planned material cost is compared. When purchasing material receiving, compare the difference between the price and the planned price, decide whether to accept the goods, so as to control the purchasing cost effectively.

System records and statistics of each work piece in each processing process of the processing time, automatic comparison of the actual processing costs and the difference between the planned costs, monitoring costs. When the actual cost exceeds the planned cost, the system will automatically alarm, notify the relevant management personnel.

Case 4. An automobile mould factory in the design of a client's new product light car front shell mold, using four pieces of expensive beryllium copper. Supplier delivery, four pieces of beryllium copper scrap with valuation, shipping price in excess of the planned price 12000 yuan, warehouse management personnel for the material delivery and warehousing, automobile mould Co., Ltd uses so mold making management management system warning this material storage prices serious beyond the planned cost, refuse storage. After the procurement supervisor and supplier negotiations, 
excluding unreasonable costs 12000 yuan, before receiving the goods.

\section{Information Management is Helpful to the Workshop Monitoring and Management}

Real time workshop monitoring can help the production supervisor to monitor the production situation of each equipment and the processing process of the mold, improve the utilization rate of equipment, control the production schedule of the work piece.

For example, when the company managers need to check the production workshop, you can view the processing equipment and the working group of the real-time production through so mold making management system system through different color markers, clearly reflect the equipment and processing group is machined workpiece and workpiece state, including each machine is doing, current machine load, is processing the workpiece is deferred, workpieces to be processed, whether has been transferred to the process, procedure, whether to postpone, material is in place, greatly reducing the management personnel working strength.

When managers need to check a set of mold production can view the Gantt chart to show the mold processing schedule, and through the comparison of the processes of the scheduled and actual process, to help management personnel mold production progress tracking.

And past production management personnel inspect the progress of the mold, to a workshop station a station to see, but can only see the main parts, small parts may simply can not understand, and even the workshop class and group leaders don't know small parts in where. Or hold a production meeting, the group leader all together, take a long time to report the progress of the mold one one. As the team leader is not the first line of the processing staff, only to their own feelings and experience to determine the progress of the mold, with a lot of error. For experienced workers, may determine the exact point, but the entire factory there is no way to ensure that every worker is very experienced, every moment is a sense of responsibility. And as long as an order in a mold can not be completed on schedule, delivery of the whole order is a problem, which is many auto mould factory before the test mode often work overtime, even overnight overtime rushed automobile mould is one of the main reasons.

\section{Information Management System to Promote the CAD Engineering Data Sharing within the Enterprise}

Due to the short time limit for a project, design drawings of the mold enterprise is difficult to enterprises such as batch production mode as doing very fine and due to frequent changes, large amount of drawings, it is impossible to send many of the non production departments drawings, which internal design information sharing. Production, business and other departments sometimes wish to measure about drawings unlabeled size, and sometimes need to check the 3D model to have a more clear understanding of the structure of the complex, these requirements are not necessary for the purchase of expensive CAD design software and for non Design Department of personnel, professional CAD software used in the lookup operation and related documents is also very convenient. If the management system and CAD engineering data link, it will greatly facilitate the production or other business sector, so that the design of information in the whole enterprise sharing.

In the Mold Making Management inte system, according to the characteristics of the operation of the mold enterprise, integrated design model browsing tool, you can browse 2D/3D documents in the system (including AutoCAD, Pro/E, UG, etc.). In this way, you can view the CAD model in any one of the company's computers. For example, technology staff to develop the process route of a workpiece can be directly click view 3D graphical buttons, by browsing tools can be used as rotation, to check the size, various section operation, is convenient for technical personnel to develop a complete and reasonable technological process; workshop workers in the machining of a work piece, with the aid of the workshop production terminal, can easily browse is processing parts of the 3D graphics, through the comparison of workpieces with 3D graphics, check whether the 
processing and correctly judge processing is complete, avoid rework and scrap. And past CNC and EDM operation personnel only 2D graphics, rework it is difficult to judge the workpiece to the final shape, often due to the CNC program omission or electrode leakage do and cause the work piece, not only a waste of resources and influence die period. In addition, this feature is very useful for the market price, purchasing and other departments of the staff are also very useful.

\section{Other Functions of Information Management in Promoting Information Sharing}

Provided by the information management system of information sharing platform, will be for the enterprise internal management provides unprecedented convenience and reduce the working pressure of the management personnel, to avoid mistakes, effective mold to ensure quality and time limit for a project.

Case 5. An automobile mould factory before the assembly, assembly fitter often purchased thimble delivery delay because of the have need of the telephone asked warehouse and purchase department, even call the supplier, to confirm the delivery time, very troublesome. If there is a link in the middle of a circuit breaker, you can not determine the exact delivery date, then the mold will not be able to determine the timing of the model.

Case 6. A large automotive die enterprise. Every night at 7:30 - 9:00 to production management of key personnel meeting. And the main topic of the meeting is review mold production (schedule, quality), when a set of mold problems. Further discussion on how to improve. Standardize the management of the mold enterprises will organize similar meetings, but it needs to be many people spend a lot of time and energy to understand mold production status, query and record all mold production information, selected from non normal dies. This will undoubtedly increase the pressure on the management staff, the valuable time and energy wasted in the statistics and collection of information, and often due to inaccurate information collected and affect decision-making.

In a with mold enterprise information management system, through the system and the management closely, will at all levels of the enterprise management and staff bring convenient information inquiry and statistics, the accurate grasp of the most timely and accurate information. For example, in so mold making management system, production management personnel can check the actual state of the production or procurement of materials, which is currently through the system, do not have a department telephone inquiries; when the progress of the understanding of mold, in addition to the system can automatically abnormal warning, management personnel can also take the initiative to enter the system, attention to the abnormal statistics. Such as statistical date design drag of mold or purchasing tardiness materials, statistical plan next week test mode of mold, statistics has not yet scheduled payments of customers, statistics this month of a supplier's account payable, etc., which can not only greatly reduce the mold management personnel's working pressure, but also can help managers to make correct decisions.

Of course, information management can also help in more ways to improve the management of mold enterprises, due to the length of the limit, here is no longer one one lists.

\section{Conclusion}

Through the improvement of Internet plus information management and traditional management closely, can promote the information management standardization of enterprises, improve the operational efficiency and market competitiveness of the enterprise, the enterprise management personnel from tedious and repetitive labor, the senior management personnel can have more time to focus on the direction of the development of enterprises, and strengthen the customer communication, open up a wider market, marketers can also further strengthen customer relationship management, looking for new customers, the development of technical director will have time to focus on new technology of automobile mould industry, strengthen technological exchanges, and constantly improve the technological level of enterprises, production supervisor can have more time to consider how to further to improve work efficiency, improve the quality and 
reduce the cost, achieve continuous improvement. Therefore, the automobile die enterprises should grasp the opportunities brought by the era of information management, and lay a solid foundation for the long-term sustainable development of automobile die and mold enterprises.

\section{References}

[1] Lin Chengquan. Mechanical design and practice [M]. Nanjing University press, 2011

[2]Lin Chengquan. Mechanical design basis curriculum design and solutions [M]. Wuhan: Huazhong University of Science and Technology press, 2009

[3] Lin Chengquan. Mechanical design foundation [M]. Wuhan: Huazhong University of Science and Technology press, 2008

[4] Lin Chengquan. Design of stamping die guide [M]. Wuhan: Wuhan University press; 2012

[5] Lin Chengquan. Typical stamping process and die design [M]. Beijing: Chemical Industry Press, 2014

[6] Lin Chengquan. Die manufacturing [M]. Beijing: Beihang University press, 2015

[7]Zhou Hongfu, Zhang Zheng, Lin Chengquan. An Ultrasonic Instrument for Osteoporosis Detecting, Lect.Notes Comput. Vol.8918, p.175-182, 2014

[8] Lin Chengquan. The research on surface metamorphic layer of punch matrix in WEDM, Applled Mechanics and Materials, Vol.500, p.481-484, 2014. 